\title{
Revitalisasi Stasiun BeSar Yogyakarta Dengan Pendekatan ARSITEKTUR KONTEKSTUAL
}

\author{
Saktian Randhy Saputra, Agus Heru Purnomo, Samsudi \\ Program Studi Arsitektur \\ Universitas Sebelas Maret Surakarta \\ Email: saktian35@gmail.com
}

\begin{abstract}
The development of rail transport is increasing every year, it can be seen in the annual report of PT. KAI 2014 with passenger volume increase of 26\% from 2013. Yogyakarta Station is located in the center of Yogyakarta that was built in 1887, became the largest station in Yogyakarta by serving a variety of class trips with destination cities in Java. Yogyakarta station currently require development to support the development of rail transport. Contextual Architecture is used as an architectural design approach for prioritizing Contextual visual linkage between the new buildings with the old building. The problems that arise in the design of this is how to maintain a visual connection between the old station buildings with new buildings that require a larger space either facade or mass laying in it. The process of creative thinking methods into methods of designing process Yogyakarta Station's revitalization. Revitalization Yogyakarta Station is done with development facilities with the construction of new buildings, so as to maintain the interconnection visual, processing performed facade on a new mass behind old buildings with elements of old buildings such as the rhythm of the windows, doors, pediment and also the color of the material.
\end{abstract}

Kata kunci: Creative Thinking, Contextual Architecture, Revitalitation, Train.

\section{PENDAHULUAN}

Transportasi merupakan faktor penting dalam kehidupan di masyarakat. Di dalam perkembangan kota, transportasi menjadi fasilitas yang harus diperhatikan, khususnya transportasi umum karena kecenderungan kehidupan di kota yang akan lebih mudah menggunakan fasilitas transportasi umum ini.

Berdasarkan data yang dilaporkan oleh PT. KAI pada annual report tahun 2014 di mana terjadi beberapa peningkatan baik fasilitas maupun pelayanan yang diberikan PT. KAI. Penyebab peningkatan ini juga dikarenakan oleh pengembangan fasilitasfasilitas pelayanan, salah satunya adalah stasiun kereta api. Stasiun Yogyakarta yang telah didirikan pada tahun 1887 (heritage.kereta-api.co.id) saat ini telah menjadi stasiun terbesar di Yogyakarta dengan melayani perjalanan berbagai kelas dengan tujuan kota-kota besar di Pulau Jawa. Terletak di pusat kota dan merupakan kawasan bersejarah Malioboro membuat Stasiun Yogyakarta menjadi daya tarik bagi wisatawan.

Berdasarkan data dari DAOP 6 Yogyakarta dan Provinsi Yogyakarta dalam
Angka, terjadi peningkatan penumpang dan barang untuk transportasi kereta untuk tiap tahunnya. Lokasi stasiun yang berada di pusat kota membawa potensi pengembangan lebih untuk mendukung perkembangan kota dan fasilitas transportasi kereta pada umumnya.

Pada tahun 2007, bangunan Stasiun Yogyakarta ini telah ditetapkan menjadi Bangunan Cagar Budaya (selanjutnya istilah ini akan disingkat menjadi $\mathrm{BCB}$ ) kelas $\mathrm{B}$ dengan nomor penetapan $\mathrm{BCB}$ PM.07/PW.007 /MKP/2007 sehingga untuk melakukan pengembangan bangunan dan fasilitas stasiun, BCB stasiun ini harus diperhatikan sehingga tidak mengurangi nilai-nilai bangunan stasiun. Arsitektur Kontekstual ini dijadikan sebagai metode perencanaan revitalisasi stasiun sehingga pengembangan bangunan baru dengan bangunan lama stasiun dapat terjaga.

Revitalisasi yang direncanakan akan memperbaiki fungsi lahan stasiun yang saat ini digunakan oleh Pedagang Kaki Lima dan perumahan sehingga mengurangi sisi keindahan stasiun. Revitalisasi yang direncanakan akan mengembangan fasilitas 
stasiun ini seperti penambahan kapasitas penguna, penambahan fasilitas pendukung fasilitas transportasi dan juga perencanaan kembali stasiun yang aman dan nyaman.

\section{METODE}

Arsitektur Kontekstual juga dapat diartikan metode desain yang melihat bangunan lama untuk dijadikan inspirasi sehingga terjadi hubungan visual antara bangunan lama dengan bangunan baru.

Untuk mencapai hal tersebut terdapat beberapa cara dalam mendesain, salah satunya adalah creative thinking (Mahmoodi 2015). Pada creative thinking terdapat tiga tahapan dalam proses desain.

1. Synthesizing

Merupakan proses menentukan unsurunsur yang akan dipertimbangkan dalam proses mendesain Arsitektur Kontekstual, baik secara fisik ataupun non fisik.

Stasiun Yogyakarta ini sendiri merupakan bangunan BCB. Arsitektur Kontekstual di sini menganalisis BCB Stasiun Yogyakarta sehingga dapat dijadikan inspirasi elemen bangunan baru.

2. Elaborating

Merupakan pengolahan ide-ide dan hasil analisis kegiatan, kebutuhan ruang dengan standar-standar perencanaan bangunan kereta api dan konservasi bangunan.

3. Imagining

Merupakan proses evaluasi terhadap ide desain untuk melihat apakah ide desain tersebut sudah cukup merepresentasikan misi dari revitalisasi Stasiun Yogyakarta.

\section{ANALISIS}

\subsection{Analisis Peruangan}

Pengguna fasilitas ini dibagi menjadi 5 secara garis besar yaitu:

1. Penumpang

Yaitu seseorang yang bepergian ke suatu kota untuk bekerja dan kembali ke kota tempat tinggalnya setiap hari, biasanya tempat tinggal mereka cukup jauh dari tempat bekerja mereka.

2. Pengantar/Penjemput

Merupakan pengantar atau pun penjemput dari pengguna fasilitas Stasiun Yogyakarta baik penumpang, pengelola, petugas servis ataupun petugas komersial.

3. Pengelola

Meliputi, kepala stasiun, administrasi, kepala operasional, bidang perlengkapan, ticketing, komunikasi,keamanan,komersial dan kebersihan.

4. Petugas Servis

Meliputi petugas informasi, petugas keamanan, teknisi, penjaga parkir, petugas medis dan petugas kebersihan.

5. Petugas Usaha Penunjang

Meliputi petugas mini market, retail dan petugas hotel transit.

Penentuan kapasistas pengguna didasarkan Peraturan Menteri 43 tahun 2011, Menteri Perhubungan tentang Rencana Induk Perkeretaapian Nasional di mana target penumpang pada tahun 2030 di Yogyakarta sebesar 20.030 .960 orang.

Tabel 1.Kebutuhan Ruang

\begin{tabular}{|l|l|}
\hline & Persyaratan Ruang \\
\hline Gedung & Hall \\
& Perkantoran Kegiatan \\
& Stasiun \\
& Loket Karcis \\
& Ruang Tunggu dan Peron \\
& Ruang Informasi \\
& Ruang Fasilitas Umum \\
& Ruang Fasilitas Keselamatan \\
& Ruang Fasilitas Keamanan \\
& Ruang Fasilitas Penyandang \\
& Cacat dan Lansia \\
& Ruang Fasilitas Kesehatan \\
\hline Gedung & Pertokoan \\
Kegiatan & Restoran \\
Penunjang & Perhotelan \\
\hline Gedung & Bengkel Muat Barang \\
Kegiatan Jasa & Pergudangan \\
Pelayanan & Parkir Kendaraan \\
Khusus & Penitipan barang \\
& Ruang ATM \\
& Bengkel Kereta \\
\hline Peron & Tinggi \\
\hline
\end{tabular}

( Peraturan Menteri Perhubungan No. 29 tahun 2011 tentang Persyaratan Teknis Bangunan Stasiun Kereta Api)

Pada Tabel 1. terlihat kebutuhan peruangan yang dibutuhkan dalam pemenuhan fasilitas stasiun lalu dilakukan analisis kebutuhan besaran ruang sehingga tercapai besaran ruang yang dibutuhkan sebagai berikut. 
Tabel 2. Rekapitulasi Besaran Ruang

\begin{tabular}{|c|c|}
\hline Area Stasiun & $18.0000 \mathrm{~m}^{2}$ \\
\hline Area Usaha Penunjang & $5.400 \mathrm{~m}^{2}$ \\
\hline Area Pengelola & $350 \mathrm{~m}^{2}$ \\
\hline Area Servis dan Utilitas & $580 \mathrm{~m}^{2}$ \\
\hline Area Parkir & $10.500 \mathrm{~m}^{2}$ \\
\hline Total Luasan & $34.830 \mathrm{~m}^{2}$ \\
\hline
\end{tabular}

Hasil rekapitulasi pada Tabel 2 ini digunakan sebagai acuan besaran ruang dari stasiun yang direncanakan.

\subsection{Analisis Pengolahan Tapak}

Lokasi Tapak Stasiun terletak di Kawasan Malioboro dengan batas-batas yaitu :

Selatan : Jl. Pasar Kembang

Utara : Jl. Suryonegaran

Barat : Jl. Tentara pelajar

Timur : Jl. Mangkubumi

Analisis pengolahan tapak stasiun ini dicapai dengan melakukan analisis area pengembangan, analisis pencapaian dan analisis view sehingga tercapai pemintakatan tapak di stasiun. Hal ini dikarenakan pada proses pengembangannya terdapat elemenelemen fisik yang harus dipertahankan.

\subsubsection{Analisis Area Pengembangan}

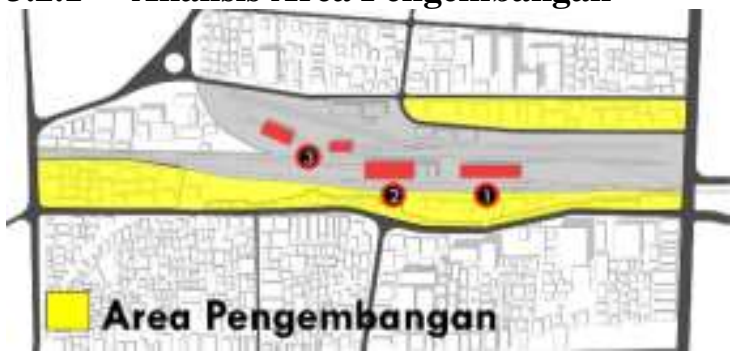

Gambar 1. Analisis Area Pengembangan

Pada Gambar 1, dapat dilihat area pengembangan yang akan digunakan adalah kawasan utara dan selatan tapak yang saat ini beralih guna menjadi kawasan pemukiman penduduk.

\subsubsection{Analisis Pencapaian}

Pencapaian ini ditentukan berdasarkan jalan, dan sirkulasi ke arah Stasiun Yogyakarta.

\subsubsection{Pencapaian kendaraan bermotor}

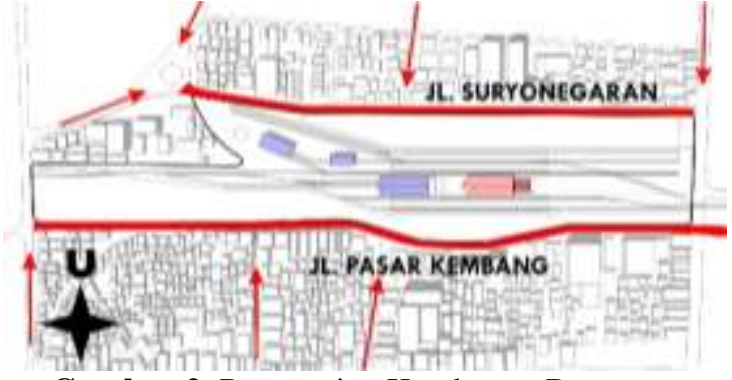

Gambar 2. Pencapaian Kendaraan Bermotor

\subsubsection{Pencapaian Pejalan Kaki}

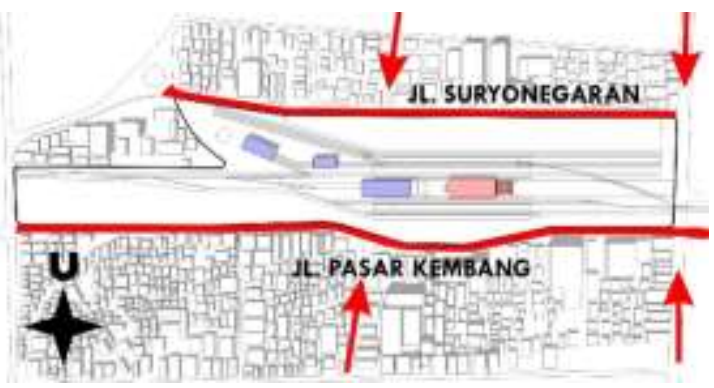

Gambar 3. Pencapaian Pejalan Kaki

\subsubsection{Analisis View dan Orientasi}

Analisis ini ditentukan berdasarkan pencapaian dan bangunan eksisting stasiun.

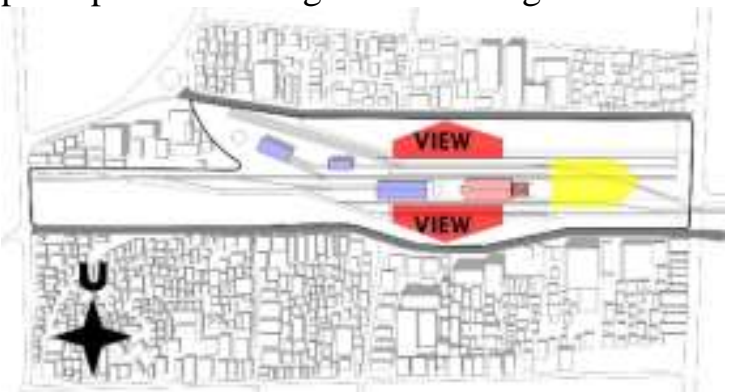

Gambar 4. View dan Orientasi Bangunan

View utama bangunan yang direncanakan mengarah ke utara dan selatan yang digunakan sebagai pintu masuk stasiun. View kedua adalah yang menghadap timur sehingga pada bagian ini pengolahan fasad bangunan harus mengesuaikan bangunan lama stasiun.

\subsubsection{Analisis Pemintakatan Akhir}

Analisis ini dicapai berdasarkan tiga analisis sebelumnya pada tapak sehingga tercapai pemintakatan yang akan direncanakan. Pemintakatan berdasarkan sifat kegiatan dan keadaan dalam tapak dilakukan seperti bangunan eksisting stasiun sebagai acuan dalam penataan peruangan. 


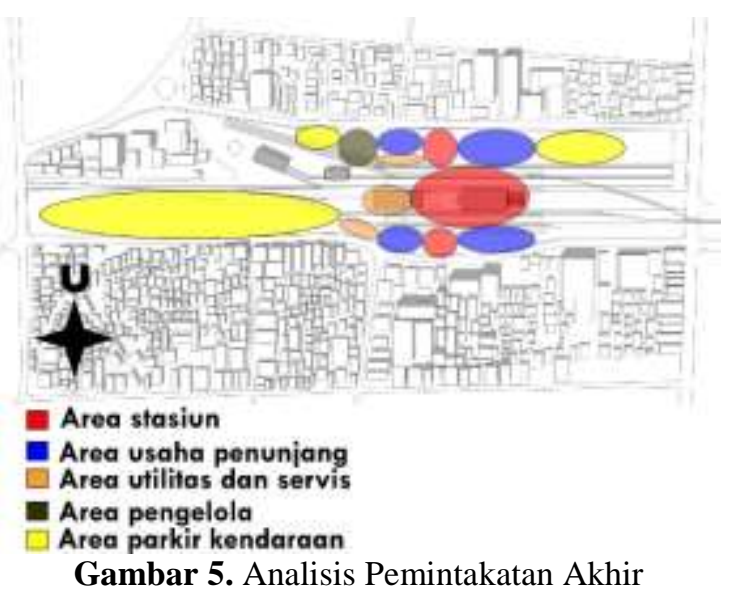

\subsection{Analisis Bentuk dan Tatanan}

Proses analisis bentuk dan tatanan ini bertujuan untuk mendapatkan konsep desain bentuk dan tatanan berdasarkan kondisi fisik dan tatanan bangunan eksisting yang didasari oleh prinsip-prinsip Arsitektur Kontekstual berdasarkan Brolin (1980) yaitu untuk memperhatikan:

1. Building silhouette.

2. Pengaturan jarak antar bangunan.

3. Jarak dari garis jalan.

4. Proporsi jendela, pintu keluar dan masuk.

5. Penempatan jalan masuk.

6. Permukaan material bangunan, finishing dan tekstur.

7. Gaya Arsitektur

8. Seni taman

Berdasarkan unsur-unsur di atas maka dalam analisis ini terbagi menjadi tiga poin proses analisis, yaitu:

\subsubsection{Analisis Bentuk Massa}

Analisis ini digunakan untuk menentukan bentuk dasar massa yang akan dipilih berdasarkan kondisi fisik massa bangunan eksisting stasiun yang ada.

Bangunan stasiun yang dipertahankan merupakan bangunan peninggalan Belanda dengan Gaya Arsitektur Indische di mana pada zaman ini bentuk dan konfigurasi massa yang ada merupakan hasil adaptasi Gaya Arsitektur Eropa dengan bentuk persegi, denah bangunan yang simetris dan penggunaan kolom-kolom tinggi (Gambar 6).
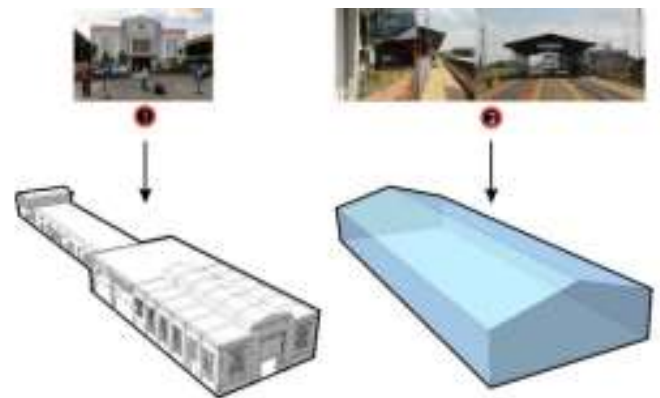

Gambar 6. Analisis Bentuk Massa Bangunan

Setelah analisis yang dilakukan, didapatkan bentuk dasar massa sesuai unsur kontekstual yaitu pemilihan massa persegi/balok. Pemilihan massa ini agar terjadi keserasian bentuk dari bangunan lama ke bangunan baru. Pengolahan massa baru dapat terinspirasi dari siluet bangunan eksisting (Gambar 7).

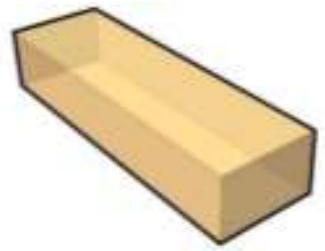

Gambar 7. Bentuk Dasar Massa Terpilih

\subsubsection{Analisis Konfigurasi Massa}

Analisis konfigurasi massa ini dilakukan untuk mendapatkan konsep penataan massa di tapak.

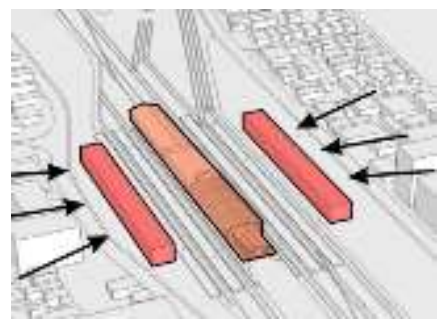

Gambar 8. Penempatan Massa Baru di Utara dan Selatan Tapak.

Pencapaian lokasi yang direncanakan menggunakan Jl. Suryonegaran (utara) dan Jl. Pasar Kembang (selatan) sehingga massa bangunan stasiun dan usaha penunjang diletakkan di kedua sisi ini untuk mempermudah pengguna stasiun. Selain itu di kedua sisi ini dibuat sebagai pintu masuk baru stasiun (Gambar. 8).

Eksisting rel yang sudah ada membuat sirkulasi dari massa di kedua sisi stasiun lama membuat pencapaiannya harus melalui 
sirkulasi vertikal sehingga digunakan massa penghubung antara massa utara dan selatan yang nantinya menuju stasiun lama lalu kemudian menuju peron stasiun (Gambar 9).

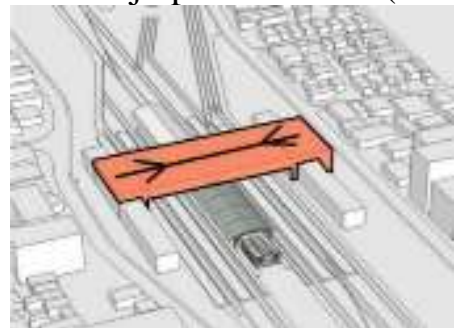

Gambar 9. Penempatan Massa Penghubung

Peletakan massa bangunan utilitas dan pengelola diletakkan di sebelah barat bangunan stasiun, hal ini dilakukan agar tidak menutupi muka dari Stasiun Yogyakarta dan mempermudah bagi pengelola stasiun maupun kegiatan servis dan utilitas untuk menuju area kerja (Gambar 10).

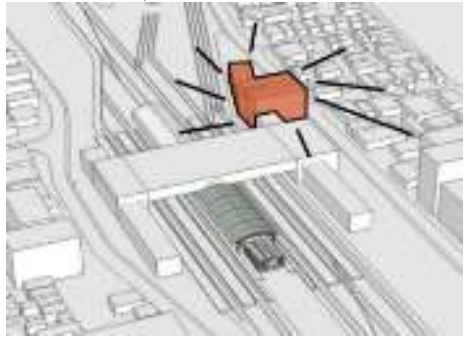

Gambar 10. Penempatan Massa Pengelola dan Utilitas

\subsubsection{Analisis Fasad}

Bangunan lama Stasiun Yogyakarta merupakan bangunan peninggalan Belanda dengan Gaya Arsitektur Indische dengan penerapan elemen-elemen jendela, pintu dan pedimen yang berciri khas khusus. Penerapan konsep fasad pada bangunan baru ini menggunakan pengulangan ritme, konfigurasi penempatan jendela ataupun mengambil garis bangunan sehingga tercapai proses pengharmonisasian bangunan lama dengan bangunan baru.

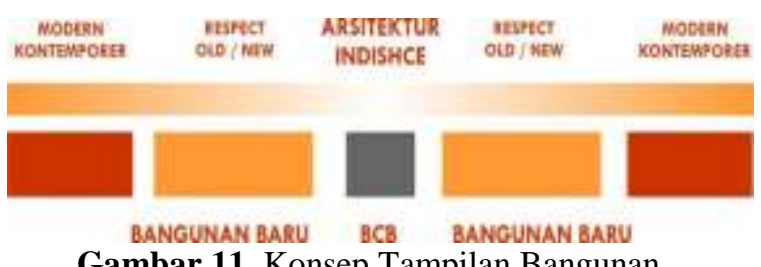

Gambar 11. Konsep Tampilan Bangunan

\subsection{Analisis Sirkulasi Bangunan}

Analisis sirkulasi stasiun ini menentukan proses sirkulasi yang ada di dalam bangunan stasiun untuk menunjang kegiatan stasiun.

Sirkulasi dibedakan menjadi dua, yaitu sirkulasi vertikal dan sirkulasi horisontal. Sirkulasi vertikal menggunakan ramp, eskalator, tangga dan lift.

1. Pencapaian menuju pintu masuk dapat dicapai secara langsung melalui Jl. Pasar Kembang (selatan) dan Jl. Suryonegaran (utara).

2. Saat memasuki bangunan, pengguna memasuki area stasiun melalui tangga, eskalator ataupun lift untuk ke area massa penghubung dan menuju ke daerah bangunan eksisting stasiun.

3. Untuk menuju ke peron, pengguna menggunakan jalur basement sehingga pengguna tidak harus menyeberangi jalur kereta sehingga keamanan lebih terjamin.

\section{KESIMPULAN (KONSEP DESAIN)}

Revitalisasi Stasiun Yogyakarta ini merupakan pengembangan fasilitas transportasi kereta di masa yang akan datang sehingga dapat menunjang kegiatan transportasi di Kota Yogyakarta dengan pendekatan Arsitektur Kontekstual.

Prinsip perencanaan kontekstual yang digunakan mengatur dalam pertimbangan perencanaan tapak, bentuk massa, konfigurasi massa dan fasad bangunan baru yang menyesuaikan bangunan lama Stasiun Yogyakarta (Gambar 12, Gambar 14, Gambar $15)$.

Pada Gambar 12 pengolahan fasad disesuaikan dengan bangunan lama yang berada di tengah-tengah tapak dengan cara menerapkan ritme-ritme dan elemen fasad pada bangunan baru sehingga terjadi keberlanjutan visual di bangunan baru.

Pada Gambar 15 merupakan hasil pengolahan tapak dari massa bangunan lama sehingga tercapai pengolahan bangunan baru di area pengembangan dari Stasiun Yogyakarta.

Pengembangan yang dilakukan yaitu penambahan kapasitas, penambahan ruang tunggu, penambahan fasilitas penunjang (retail, penginapan) seperti pada Gambar 13. Pengembangan ini juga memperbaiki 
pelayanan stasiun sesuai dengan standar perencanaan fasilitas transportasi stasiun.

Nama Stasiun : Stasiun Besar Yogyakarta Lokasi : Jl. Pasar Kembang dan Jl. Suryonegaran

Luas Lahan $\quad: 130.000 \mathrm{~m}^{2}$

Luar Bangunan : $40.000 \mathrm{~m}^{2}$

Daya Tampun : 3000 orang / Jam

Kegiatan : Transportasi Umum Kereta

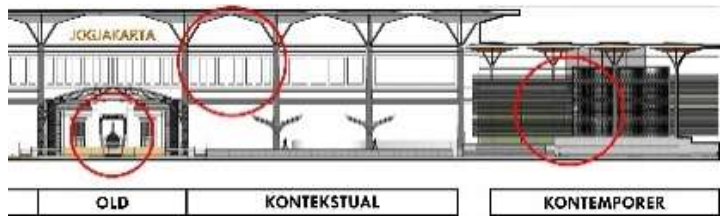

Gambar 12. Fasad Timur Stasiun Yogyakarta



Gambar 13. Eksterior Pintu Masuk Utara/Selatan Stasiun Yogyakarta

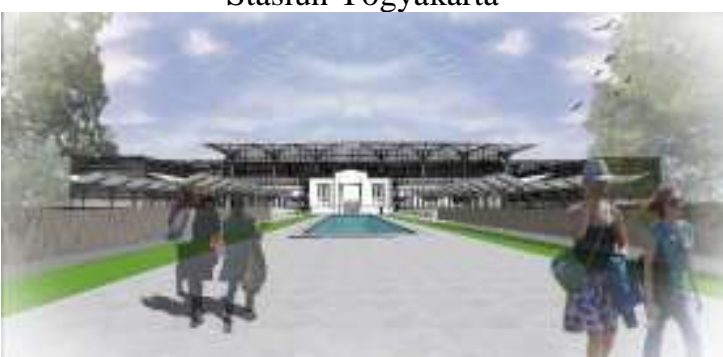

Gambar 14. Eksterior Pintu Masuk Timur Stasiun

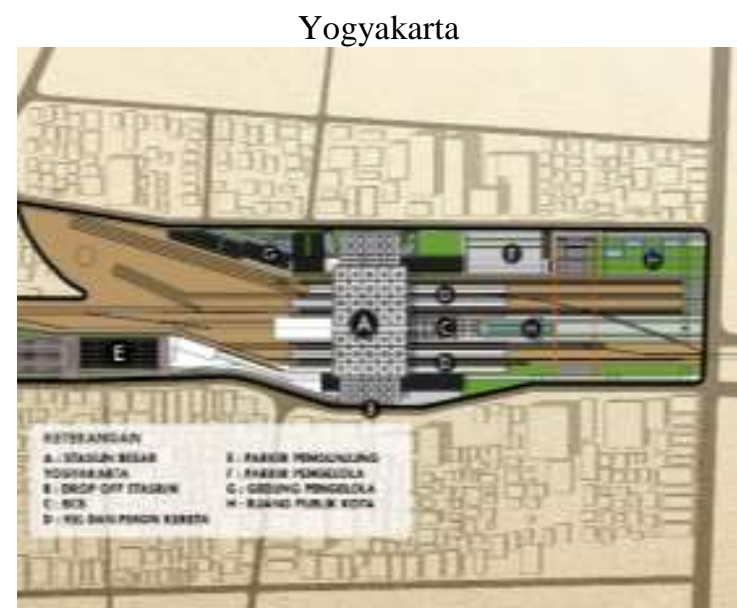

Gambar 15. Situasi Stasiun Yogyakarta

\section{REFERENSI}

Annual Report PT. KAI 2014. Accessed Oktober 10.

https://www.kereta-api.co.id/

Brolin, Brent C. 1980. Architecture in Context. Van Nostrand Reinhold Company

Mahmoodi, Amir. 2015. “The Design Process In Architecture A Pedagogic Approach Using Interactive Thinking."

University o Leeds. Accessed November 6.

PM Perhub No. 29. 2011. Persyaratan Teknis Bangunan Stasiun Kereta Api. jdih.dephub.go.id

PT. KAI. tt. Pedoman Pelestarian Bangunan Perkereta-apian. Accessed November 15. heritage.kereta-api.co.id

W. Griffin, Kenneth. 2004. Transit Facilities. Hoboken: John Wiley \& Sons, Inc.

Yogyakarta dalam Angka 2014. Accessed Oktober 10

yogyakarta.bps.go.id 